\title{
Long non-coding RNA RAB11B-AS1 prevents osteosarcoma development and progression via its natural antisense transcript RAB11B
}

\author{
Zhixu Chen ${ }^{1, *}$, Zezheng Liu ${ }^{1,}{ }^{*}$, Yang Yang ${ }^{1}$, Zhaoyin Zhu ${ }^{1}$, Ridong Liang ${ }^{1}$, Bin Huang ${ }^{1}$, \\ Di Wu ${ }^{2}$, Lei Yang ${ }^{2}$, Hai Lu${ }^{1}$, Dadi Jin' ${ }^{1}$ and Qingchu Li ${ }^{1}$ \\ ${ }^{1}$ Academy of Orthopedics, Guangdong Province, Department of Orthopedics, The Third Affiliated Hospital, Southern Medical \\ University, Guangzhou 510630, China \\ ${ }^{2}$ The State Key Lab of Respiratory Disease, The Institute for Chemical Carcinogenesis, Collaborative Innovation Center for \\ Environmental Toxicity, Guangzhou Medical University, Guangzhou 510182, China \\ *These authors contributed equally to this work \\ Correspondence to: Qingchu Li, email: lqc16@263.net \\ Keywords: InC-RAB 1 1B-AS1; osteosarcoma; RAB 11B; proliferation; invasion \\ Received: January 25, 2017 Accepted: December 05, 2017 Epub: January 13, 2018 Published: June 01, 2018
}

Copyright: Chen et al. This is an open-access article distributed under the terms of the Creative Commons Attribution License 3.0 (CC BY 3.0 ), which permits unrestricted use, distribution, and reproduction in any medium, provided the original author and source are credited.

\section{ABSTRACT}

Long non-coding RNAs (IncRNAs) have been shown to exert essential roles in development and progression of tumors. Here we discovered a novel IncRNA, RAB11B antisense RNA (RAB11B-AS1), which is markedly down-regulated in human osteosarcoma (OS) and associated with OS metastasis and poor prognosis. We find that reduction of RAB11B-AS1 significantly facilitates proliferation, migration and invasiveness and prevents apoptosis of OS cells and results in lower sensitivity to cisplatin in these cells. In contrast, up-regulation of RAB11B-AS1 suppresses the aggressive behaviors of OS cells. Mechanistically, down-regulation of RAB11B-AS1 elevates its sense-cognate gene RAB11B expression at both mRNA and protein levels. RAB11B-AS1 expression correlates negatively with RAB11B expression in OS tissues. Luciferase reporter assay illuminated that RAB11B-AS1 regulates RAB11B expression through antisense pairing. Most importantly, all the effects of RAB11BAS1 were abrogated by RAB11B down-regulation. Thus our findings revealed that Inc-RAB11B-AS1 prevents osteosarcoma development and progression via inhibiting RAB11B expression, indicating Inc-RAB11B-AS1 as a potential therapeutic target for osteosarcoma.

\section{INTRODUCTION}

Osteosarcoma (OS), the most common primary bone sarcoma, is one of the malignant tumors threating teenagers' life and health seriously $[1,2]$. Because of lacking effective diagnostic methods, 80 percent of the lymph node micrometastasis of osteosarcoma cannot be detected [3]. Most patients are in middle or advanced stage when they were diagnosed and thus had a bad prognosis. Currently, the main treatment strategy of osteosarcoma is surgical resection with adjuvant chemotherapy. 5-year survival rates for patients with non-metastatic disease reported above $60 \%$ to $70 \%[4,5]$, while those with metastatic diseases or relapses result in much poorer prognosis [6]. Therefore, it is exigent to develop novel targets for the diagnosis, treatment and prognosis of osteosarcoma.

Currently, the long non-coding RNA (lncRNA), an RNA molecular that is longer than 200 nucleotides and cannot be translated into a protein, attracts more and more attention. LncRNAs involve in the regulation of almost all life activities, while their known prime function is to regulate expression of genes in different levels, such as epigenetic modifications, endonuclear transportation, transcription, post-transcription and so on [7, 8]. Irregular IncRNA expression has been shown to be concerned with many diseases including tumor. Tumor-related lncRNA is almost twice protein-encoding genes that concerned with 
tumor [9]. Moreover, lncRNA closely associates with the biological behavior of the tumor, including occurrence, development, invasion and metastasis of tumors [10-12]. Due to these characteristics, lncRNA has potential role in early diagnosis, treatment, and prognosis of tumors. When it comes to osteosarcoma, overexpression of lncRNA HOTTIP increases chemoresistance of osteosarcoma cell by activating the $\mathrm{Wnt} / \beta$-catenin pathway [13]. LncRNA FGFR3-AS1 promotes osteosarcoma growth through regulating its natural antisense transcript FGFR3 [14]. Moreover, it is reported that lncRNA SNHG12 promote the osteosarcoma cells proliferation and migration in vitro [15]. But in fact, quite few investigations have been executed on the role of IncRNAs in osteosarcoma until recently, and the underlying mechanisms are largely unknown.

Recently, we discovered a novel lncRNA named $R A B 11 B-A S 1$ by bioinformatic analysis. $R A B 11 B-A S 1$ locates at chromosome $19 \mathrm{q} 13.2$ and belongs to Ras family. $R A B$ gene is well known for its role in tumor activation and progression. $R A B 11$ participates in a great many life activities, such as endocytic membrane traffic, autophagy, invasion of cells and so on [16]. The role of $R A B 11$ has been implied in many types of tumor, including breast cancer, colorectal carcinoma and skin carcinoma [17-19]. However, the biological function of $R A B 11 B-A S 1$ in tumor remains unclear.

In the present study, we aimed to investigate the potential role of $R A B 11 B-A S 1$ in osteosarcoma and uncover the underlying mechanisms. Our results suggested that $R A B 11 B-A S 1$ significantly suppresses proliferation, migration and invasiveness and promotes apoptosis of OS cells and elevates sensitivity of these cells to cisplatin. Mechanistically, aberrant hyper-methylation of the promoter region might be responsible for decreased $R A B 11 B-A S 1$ in osteosarcoma and $R A B 11 B-A S 1$ exerts its effects in osteosarcoma via its sense-cognate gene $R A B 11 B$. Thus our study identified lnc- $R A B 11 B-A S 1$ as a novel biomarker and therapeutic target for osteosarcoma.

\section{RESULTS}

\section{Lnc- $R A B 11 B-A S 1$ exhibits decreased expression in osteosarcoma tissues, and correlates with poor prognosis}

Firstly, we detected lnc-RAB11B-AS1 expression in osteosarcoma tissues and paired non-neoplastic tissues from 24 patients. As revealed in Figure 1A, lnc-RAB11B-AS1 presented a significant decrease in osteosarcoma tissues as compared with their paired nonneoplastic tissues. Next, we examined the correlation between $R A B 11 B-A S 1$ expression and clinicopathological characteristics of the 24 osteosarcoma samples. Lnc$R A B 11 B-A S 1$ correlated negatively with clinical stage of tumor, indicating a role of $\operatorname{lnc}-R A B 11 B-A S 1$ in development and poor prognosis of osteosarcoma (Table 1). We then assessed the subcellular location of the IncRNA. Osteosarcoma cell lines HOS and U2OS were chosen randomly and subjected to nuclear and cytoplasmic fractionation analysis. The majority of lnc$R A B 11 B-A S 1$ was shown to be localized in nucleus other than in cytoplasm of cells, suggesting the lncRNA as a transcriptional regulator in osteosarcoma cells (Figure 1B).

\section{Lnc- $R A B 11 B-A S 1$ abrogates osteosarcoma cells proliferation, migration and invasion and facilitated their apoptosis in vitro}

We then examine the role of lnc-RAB11B-AS1 in osteosarcoma cells. We first tested the proliferative rate of osteosarcoma cells with knockdown or overexpression of lnc-RAB $11 B-A S 1$ using CCK-8 assay. As revealed in Figure $2 \mathrm{~A}$ and Supplementary Figure 1A, up-regulation of lnc-RAB $11 B-A S 1$ resulted in decreased proliferative rate of osteosarcoma cells, while down-regulation of lnc-RAB11B-AS1 accelerated proliferation of them. These results suggested that lnc-RAB11B-AS1 inhibits osteosarcoma cells proliferation. To investigate the underlying mechanism, flow cytometry was then performed in the cells to evaluate cell cycle. HOS cells with reduced lnc-RAB11B-AS1 showed decreased number in G0-G1 phase and increased number in the $\mathrm{S}$ phase, while cells with elevated lnc-RAB11B-AS1 showed the contrary. These results were copied in U2OS cells (Figure $2 \mathrm{~B}$ and Supplementary Figure1B), indicating that lnc$R A B 11 B-A S 1$ suppress osteosarcoma cells proliferation by increasing the number of them in G0-G1 phase and reducing the number in the $\mathrm{S}$ phase.

Apoptosis of both HOS and U2OS cells was abrogated by $\operatorname{lnc}-R A B 11 B-A S 1$ down-regulation and was facilitated by lnc-RAB11B-AS1 up-regulation (Figure 2C and Supplementary Figure 2), suggesting that lnc-RAB11B-AS1 promote apoptosis of osteosarcoma cells. In the migration assay, down-regulation of $\operatorname{lnc}-R A B 11 B-A S 1$ promoted migration of HOS and U2OS cells, while up-regulation of the lncRNA presented contrary effect on the cells (Figure 3A and Supplementary Figure 3A). These results suggested inhibitory role of lnc- $R A B 11 B-A S 1$ on osteosarcoma cells migration. Results from invasion assay showed that lnc$R A B 11 B-A S 1$ impair invasion of osteosarcoma cells (Figure $3 \mathrm{~B}$ and Supplementary Figure $3 \mathrm{~B}$ ).

\section{Lnc-RAB11B-AS1 suppresses osteosarcoma growth in vivo}

To test the results presented above in vivo, we injected mice with HOS cells that stably expressed either pEZ-Lv206lnc-RAB11B-AS1 or psi-LVRH1MP- lnc-RAB11B-AS1 and monitored tumor growth. HOS cells with overexpressed lnc- $R A B 11 B-A S 1$ resulted in slower growth rate of tumor 
Table 1: Correlation between the clinicopathological characteristics and expression of $R A B 11 B$ AS1

\begin{tabular}{|c|c|c|c|c|}
\hline \multirow[b]{2}{*}{ Factors } & \multirow{2}{*}{$\begin{array}{l}\text { No of patients } \\
(n=24), n(\%)\end{array}$} & \multicolumn{2}{|c|}{$R A B 11 B-A S 1$ expression } & \multirow[b]{2}{*}{$P^{\text {a value }}$} \\
\hline & & $\begin{array}{c}\text { Low }(n=12) \\
n(\%)\end{array}$ & $\begin{array}{c}\text { High }(n=12), \\
n(\%)\end{array}$ & \\
\hline \multicolumn{5}{|l|}{ Age } \\
\hline$\leq 20$ & $6(25.0)$ & $2(33.3)$ & $4(66.7)$ & 0.640 \\
\hline$>20$ & $18(75.0)$ & $10(55.6)$ & $8(44.4)$ & \\
\hline \multicolumn{5}{|l|}{ Gender } \\
\hline Male & $16(66.7)$ & $9(56.2)$ & $7(43.8)$ & 0.667 \\
\hline Female & $8(33.3)$ & $3(37.5)$ & $5(62.5)$ & \\
\hline \multicolumn{5}{|l|}{ Location } \\
\hline Tibia/femur & $20(83.3)$ & $11(55.0)$ & $9(45.0)$ & 0.590 \\
\hline Elsewhere & $4(16.7)$ & $1(25.0)$ & $3(75.0)$ & \\
\hline \multicolumn{5}{|l|}{ Histological type } \\
\hline Osteoblastoma & $14(58.3)$ & $9(64.3)$ & $5(35.7)$ & 0.214 \\
\hline Else & $10(41.7)$ & $3(30.0)$ & $7(70.0)$ & \\
\hline \multicolumn{5}{|l|}{ Differentiated degree } \\
\hline High/middle & $4(16.7)$ & $1(25.0)$ & $3(75.0)$ & 0.590 \\
\hline Low/undifferentiation & $20(83.3)$ & $11(55.0)$ & $9(45.0)$ & \\
\hline \multicolumn{5}{|l|}{ TNM } \\
\hline T1N0M0 & $6(25.0)$ & $4(66.7)$ & $2(33.3)$ & 0.640 \\
\hline T2N0M0 & $18(75.0)$ & $8(44.4)$ & $10(55.6)$ & \\
\hline \multicolumn{5}{|l|}{ Clinical stage } \\
\hline $\mathrm{I}$ & $11(45.8)$ & $2(18.2)$ & $9(81.8)$ & 0.012 \\
\hline II & $13(54.2)$ & $10(76.9)$ & $3(23.1)$ & \\
\hline
\end{tabular}

${ }^{\text {a }}$ Fisher's Exact Test $P$ value

The expression of $R A B 11 B-A S 1$ is measured by qRT-PCR and the cut-off based on the median of the expression of 24 osteosarcoma tissues and classed as low or high $R A B 11 B-A S 1$ expression.

in mice, while those with reduced lnc- $R A B 11 B-A S 1$ caused higher growth rate of tumor (Figure 4). To uncover the underlying mechanisms, we performed Ki-67 and TUNEL assay in tumor slices to determine proliferation and apoptosis of osteosarcoma cells in vivo. Osteosarcoma cells with decreased lnc-RAB 11B-ASl showed accelerated proliferation rate, while those with elevated lncRNA exhibited slowed proliferation (Figure 5). Results from TUNEL assay revealed that lnc-RAB11B-AS1 facilitated apoptosis of osteosarcoma cells in vivo (Figure 6). These findings suggest that lnc$R A B 11 B-A S 1$ inhibits osteosarcoma growth in vivo.

\section{Lnc-RAB11B-AS1 enhances sensitivity of osteosarcoma cells to cisplatin}

Genetic differences in tumors influence their response to chemotherapeutic agents and cause inter-individual differences in treatment outcomes. Cisplatin is a common drug used for treating osteosarcoma. We next assessed whether 1 nc- $R A B 11 B-A S 1$ has any role in chemotherapy of osteosarcoma by cisplatin. Treatment with increasing concentrations of cisplatin caused a dose dependent death of osteosarcoma cells. Over-expression of lnc-RAB11B-AS1 accelerated the death of osteosarcoma cells, while reduction of lnc-RAB11B-AS1 resulted in resistance of the cells to cisplatin (Figure 7A and Supplementary Figure 4A). Next, we calculated the half maximal inhibitory concentration (IC50) of osteosarcoma cells (Figure 7B and Supplementary Figure $4 \mathrm{~B}$ ), results from which maintained the conclusion that lnc-RABIIB-AS1 enhanced the sensitivity of osteosarcoma cells to cisplatin.

\section{Lnc- $R A B 11 B-A S 1$ correlates negatively with its sense-cognate gene $R A B 11 B$ in osteosarcoma cells.}

We next investigated the mechanisms by which lnc-RAB11B-AS1 exerts the effects depicted above in osteosarcoma cells. Results from bioinformatic analysis 


\begin{tabular}{|c|c|c|c|c|}
\hline \multirow[b]{2}{*}{ Factors } & \multirow[b]{2}{*}{$\begin{array}{c}\text { No of tissues } \\
(n=145), n(\%)\end{array}$} & \multicolumn{2}{|c|}{$R A B 11 B$ expression } & \multirow[b]{2}{*}{$P^{\mathrm{b}}$ value } \\
\hline & & $\begin{array}{c}\text { Low } \\
(n=71) \\
n(\%)\end{array}$ & $\begin{array}{c}\text { High } \\
(n=74), \\
n(\%)\end{array}$ & \\
\hline \multicolumn{5}{|l|}{ Age } \\
\hline$\leq 20$ & $50(34.5)$ & $18(36.0)$ & $32(64.0)$ & 0.023 \\
\hline$>20$ & $95(65.5)$ & $53(55.8)$ & $42(44.2)$ & \\
\hline \multicolumn{5}{|l|}{ Gender } \\
\hline Male & $91(62.8)$ & $49(53.8)$ & $42(46.2)$ & 0.127 \\
\hline Female & $54(37.2)$ & $22(40.7)$ & $32(59.3)$ & \\
\hline \multicolumn{5}{|l|}{ Location } \\
\hline Tibia/femur & 98 (67.6) & $44(44.9)$ & $54(55.1)$ & 0.157 \\
\hline Elsewhere & $47(32.4)$ & $27(57.4)$ & $20(42.6)$ & \\
\hline \multicolumn{5}{|l|}{ Histological type } \\
\hline Osteoblastoma & $99(68.3)$ & $43(43.4)$ & $56(56.6)$ & 0.051 \\
\hline Else & $46(31.7)$ & $28(60.9)$ & $18(39.1)$ & \\
\hline \multicolumn{5}{|l|}{ Differentiated degree } \\
\hline High/middle & $52(35.9)$ & $36(69.2)$ & $16(30.8)$ & $<0.001$ \\
\hline Low/undifferentiation & $93(64.1)$ & $35(37.6)$ & $58(62.4)$ & \\
\hline \multicolumn{5}{|l|}{ TNM } \\
\hline T1N0M0 & $26(17.9)$ & $10(38.5)$ & $16(61.5)$ & 0.237 \\
\hline T2N0M0 & $119(82.1)$ & $61(51.3)$ & $58(48.7)$ & \\
\hline \multicolumn{5}{|l|}{ Clinical stage } \\
\hline I & $27(18.6)$ & $19(70.4)$ & $8(29.6)$ & 0.014 \\
\hline II & $118(81.4)$ & $52(44.1)$ & $66(55.9)$ & \\
\hline
\end{tabular}

${ }^{6}$ Pearson Chi-Square $P$ value.

The expression of RAB11B is reflected by the histochemistry score(H-score).H-score is equal to $\Sigma\left(\right.$ pi $\left.^{*} \mathrm{i}\right)$, which the 'pi' means the percentage of RAB11B-positive cells in the section and the ' $\mathrm{i}$ ' means the tint strength of the cells. And the H-score cutoff based on the median of the $\mathrm{H}$-score of 145 osteosarcoma tissues and classed as low $(\mathrm{H}$-score $\leq 25)$ or high $(\mathrm{H}$-score $>25)$ RAB11B expression.

showed that $\operatorname{lnc}-R A B 11 B-A S 1$ and $R A B 11 B$ formed a 'head-to-tail' pairing pattern with 448 nucleotides full complementarity (Figure $8 \mathrm{~A}$ ). Thus we next examined the association between lnc-RAB11B-AS1 and $R A B 11 B$ mRNA. Expressions of $R A B 11 B$ were detected in the 24 paired tissue samples mentioned above. A significant increase of $R A B 11 B$ level was observed in osteosarcoma tissues as compared with the corresponding non-neoplastic tissues (Figure 8B). Moreover, correlational analysis showed a negative correlation between $\operatorname{lnc}-R A B 11 B-A S 1$ and $R A B 11 B$ expression in the tissues (Figure $8 C$ ). To validate these results in vitro, we disrupted lnc-RAB11B$A S 1$ expression in osteosarcoma cell lines, and found significant increase of $R A B 11 B$ mRNA in these cells. On the contrary, up-regulation of lnc- $R A B 11 B-A S 1$ resulted in reduction of $R A B 11 B$ mRNA in osteosarcoma cells (Figure 8D, Figure 8E, Supplementary Figure 5A and Supplementary Figure 5B). Results from western blotting further confirmed these results at the protein level (Figure
$8 \mathrm{~F}$ and Supplementary Figure 5C). Next, luciferase reporter assay was conducted to explore the interaction between Inc-RAB11B-AS1 and the RAB11B. Reduction of lnc- $R A B 11 B-A S 1$ caused increased luciferase activity of pGL3-Promoter-RAB11B in osteosarcoma cells, while up-regulation of the lncRNA resulted in contrary effect (Figure 8G and Supplementary Figure 5D). These results demonstrated negative correlation between lnc-RAB11B$A S 1$ and $R A B 11 B$ in osteosarcoma cells.

\section{Lnc-RAB11B-AS1 prevents osteosarcoma progression via down-regulating $\mathrm{RAB} 11 \mathrm{~B}$}

We then explored the effects of $R A B 11 B$ on osteosarcoma cells. In CCK-8 assay, osteosarcoma cells with reduced $R A B 11 B$ displayed a lower proliferation potential than control cells (Figure 9B and Supplementary Figure 6A), suggesting positive role of $R A B 11 B$ in osteosarcoma cells proliferation. Flow cytometer analysis 
of cell cycle revealed that $R A B 11 B$ increased number of cells in $\mathrm{S}$ phase (Figure $9 \mathrm{C}$ and Supplementary Figure $6 \mathrm{~B})$. Down-regulation of $R A B 11 B$ increased number of apoptotic osteosarcoma cells, indicating an inhibitory role of $R A B 11 B$ in apoptosis of these cells (Figure 9D and Supplementary Figure 7). In addition, we detected the expression of $R A B 11 B$ in the osteosarcoma tissue chips by immunochemistry and examined correlation between $R A B 11 B$ and the clinicopathological characteristics of osteosarcoma. $R A B 11 B$ negatively correlated with the degree of tumor differentiation and age, and positively advanced clinical stage (Figure 9E and Table 2). These results revealed that $R A B 11 B$ promotes osteosarcoma progression.

We next define the potential role of $R A B 11 B$ in mediating the effect of lnc-RAB11B-AS1 in osteosarcoma cells. As depicted above, down-regulation of lnc- $R A B 11 B$ $A S 1$ induced proliferation, migration and invasion and impaired apoptosis of osteosarcoma cells. All of these effects were reversed by $R A B 11 B$ down-regulation (Figure 10 and Supplementary Figures 8-10). These results suggested that lnc- $R A B 11 B-A S 1$ exerts its role in osteosarcoma cells via regulating $R A B 11 B$ negatively.

\section{Aberrant hyper-methylation of the promoter region contributes to decreased Inc-RAB11B-AS1 in osteosarcoma.}

Emerging evidences now support that DNA methylation is essentially involved in dysregulated lncRNAs expression in a variety of cancer. In light of this notion, we detected the methylation level of $\mathrm{CpG}$ island in 1 c $-R A B 11 B-A S 1$ promoter region to explore the upstream molecular mechanism of down-regulated lnc- $R A B 11 B-A S 1$ in osteosarcoma. We found a $\mathrm{CpG}$ island from $56 \mathrm{bp}$ upstream to $609 \mathrm{bp}$ downsteam of the

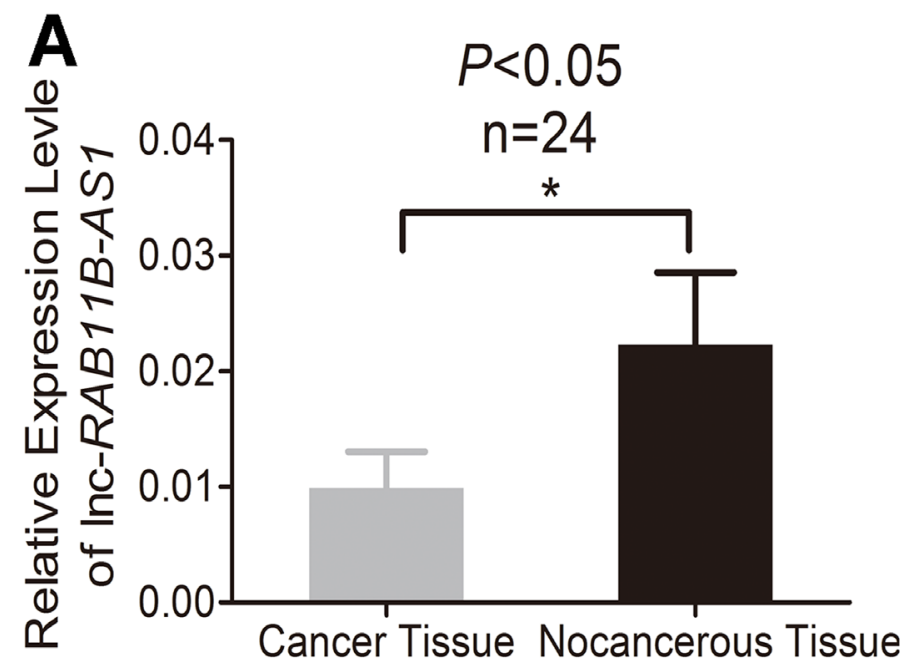

transcription start site (TSS) in the promoter region of lnc$R A B 11 B-A S 1$ (Figure 11A). Methylation level of the $\mathrm{CpG}$ island was assayed in six osteosarcoma and compared with six paired non-neoplastic tissues after bisulphite conversion of genomic DNA. The mean methylation level of the $\mathrm{CpG}$ island in $1 \mathrm{c}-\mathrm{R} A B 11 B-A S 1$ promoter region in osteosarcoma was significantly higher than that in the control samples (Figure 11B). We also investigate the possible associations between methylation level of the $\mathrm{CpG}$ island and lnc-RAB11B-AS1 expression. As shown in Figure $11 \mathrm{C}$, lnc-RAB11B-AS1 expression correlates negatively with methylation level of the $\mathrm{CpG}$ island in osteosarcoma. These data suggest that DNA hypermethylation in the promoter region of lnc-RAB $11 B-A S 1$ might play an important role in down-regulation of lnc$R A B 11 B-A S 1$ in osteosarcoma.

\section{DISCUSSION}

In recent years, the role of IncRNAs in tumor development and progression attracts more and more investigations. As one kind of the lncRNAs, the antisense lncRNAs get increasing attentions. Previous studies showed critical roles of natural antisense transcripts in many physiological or pathology processes, including tumorigenesis, through regulating sense genes expression [20-23]. Respectable researches have been executed on the antisense lncRNAs in different tumors. For example, the FEZF1-AS1 is found to be markedly up-regulated in human primary colorectal carcinoma (CRC) and associated with CRC metastasis and poor prognosis [24]. $H I F 1 A-A S 2$ was up-regulated in bladder cancer tissues and cells, and $H I F 1 A-A S 2$ expression level in bladder cancer tissues is positively associated with advanced clinical pathologic grade and TNM phase [25]. In addition, EPB41L4A-AS2 inhibits tumor proliferation and

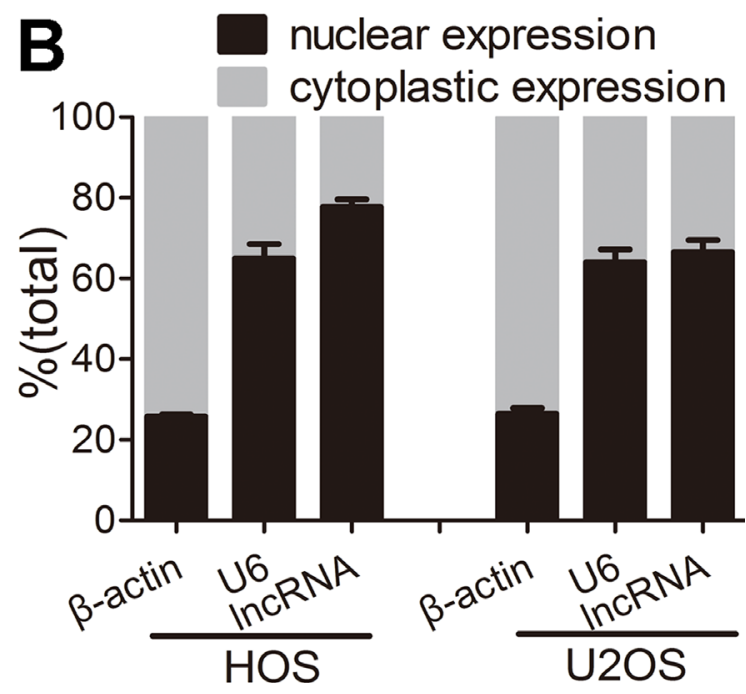

Figure 1: Osteosarcoma tissues exhibits lower Inc-RAB11B-AS1 expression. (A) Expression of lnc- $R A B 11 B-A S 1$ in osteosarcoma tissues $(n=24)$ compared with the paired non-neoplastic tissues $(n=24)$. (B) Subcellular location of lnc-RAB11B-AS1. Data was presented as mean $\pm \mathrm{SD}$. The results were reproducible in three independent experiments. ${ }^{*} P<0.05$. 

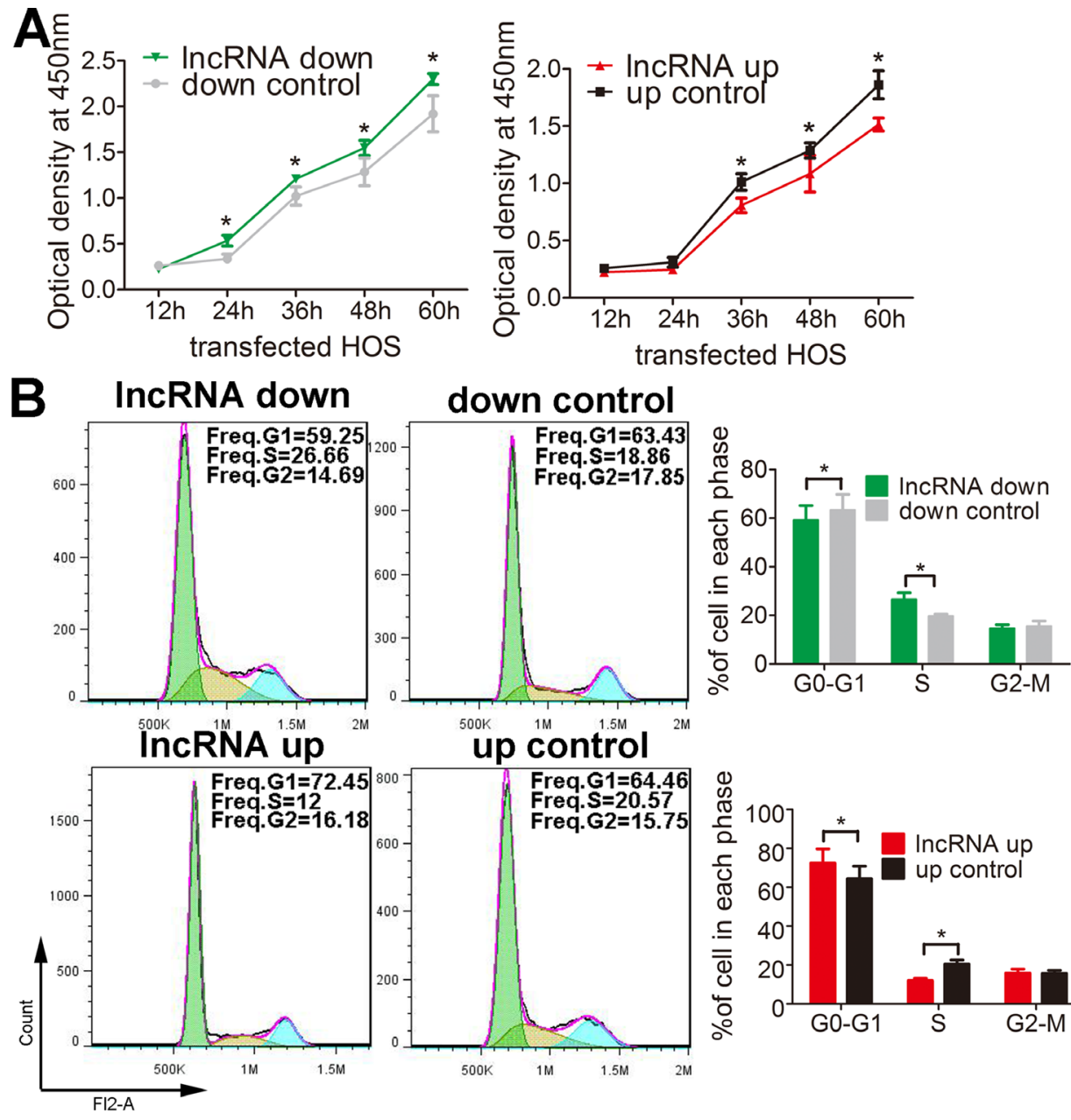

up control

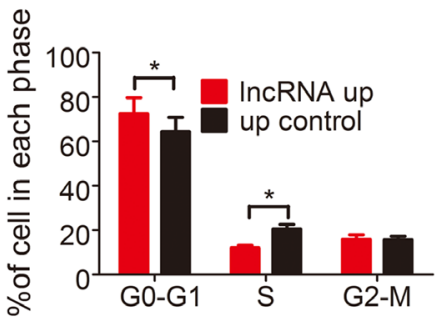

C IncRNA down
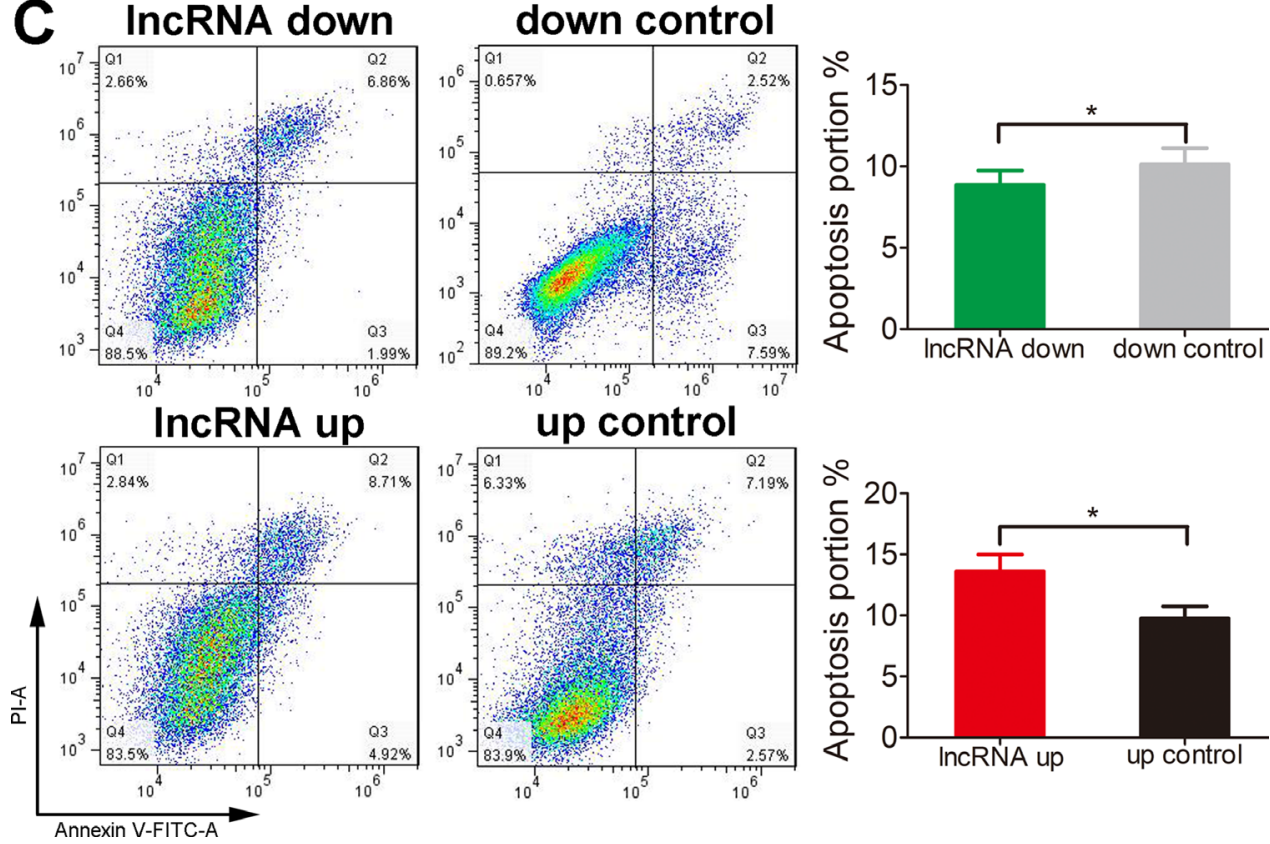

Figure 2: Inc-RAB11B-AS1 inhibits HOS cells proliferation and promotes HOS cells apoptosis. (A) Proliferation of HOS cells with up-regulated (up) or down-regulated (down) lnc-RAB11B-AS1 was determined by CCK-8 assay. (B) Flow cytometer analysis of the cell cycle distribution of HOS cells with up-regulated or down-regulated lnc-RAB11B-AS1. (C) Annexin V-FITC/PI apoptosis assay of HOS cells with up-regulated or down-regulated lnc-RAB11B-AS1. Data was presented as mean $\pm \mathrm{SD}$. The results were reproducible in three independent experiments. ${ }^{*} P<0.05$. 
is associated with favorable prognoses in breast cancer and other solid tumors [26]. Nonetheless, functions of quite a number of antisense lncRNAs in osteosarcoma remain unclear.

In this study, we found that $\operatorname{lnc}-R A B 11 B-A S 1$, a newfound long non-coding RNA, is down-regulated in osteosarcoma tissues as compared with pair-matched noncancerous tissues. Moreover, we identified the role of lnc-RAB11B-AS1 in osteosarcoma cells. Our results demonstrated that lnc-RAB $11 B-A S 1$ inhibits osteosarcoma cells proliferation, cell cycle progression, invasion and migration in vitro and prevents tumor growth in vivo, indicating lnc- $R A B 11 B-A S 1$ as an anti-oncogene in osteosarcoma. Mechanistically, lnc-RAB11B-AS1 exerts these effects by binding to $R A B 11 B$ 5'UTR and reducing $R A B 11 B$ expression. The correlation between $R A B 11 B$ and $R A B 11 B-A S 1$ in osteosarcoma tissues supports the role of $R A B 11 B$ in mediating the effects of $R A B 11 B$ $A S 1$. In addition, luciferase reporter assay illustrated the interaction between $R A B 11 B-A S 1$ and the $R A B 11 B$. Most importantly, all the effects of lnc-RAB11B-AS1 were abrogated by $R A B 11 B$ down-regulation, which validated that lnc-RAB11B-AS1 exerts its function in osteosarcoma via $R A B 11 B$.

Recently, epigenetic silencing of tumor-suppressor lncRNA by aberrant DNA hyper-methylation attracts increasing attention in a variety of cancer [27-29]. To explore the epigenetic mechanism by which lnc$R A B 11 B-A S 1$ is regulated in osteosarcoma, we assessed the DNA methylation status of promoter region of lnc$R A B 11 B-A S 1$ in six paired osteosarcoma and adjacent normal samples. As expected, lnc-RAB11B-AS1 expression correlates negatively with DNA methylation of its promoter region. We speculate that hypermethylation of the promoter region might abrogate lnc$R A B 11 B-A S 1$ expression, and inhibition of methylation in lnc-RAB11B-AS1 might be beneficial for treatment of osteosarcoma.

A big challenge in treatment of osteosarcoma is its resistance to the standard chemotherapy. Cisplatin
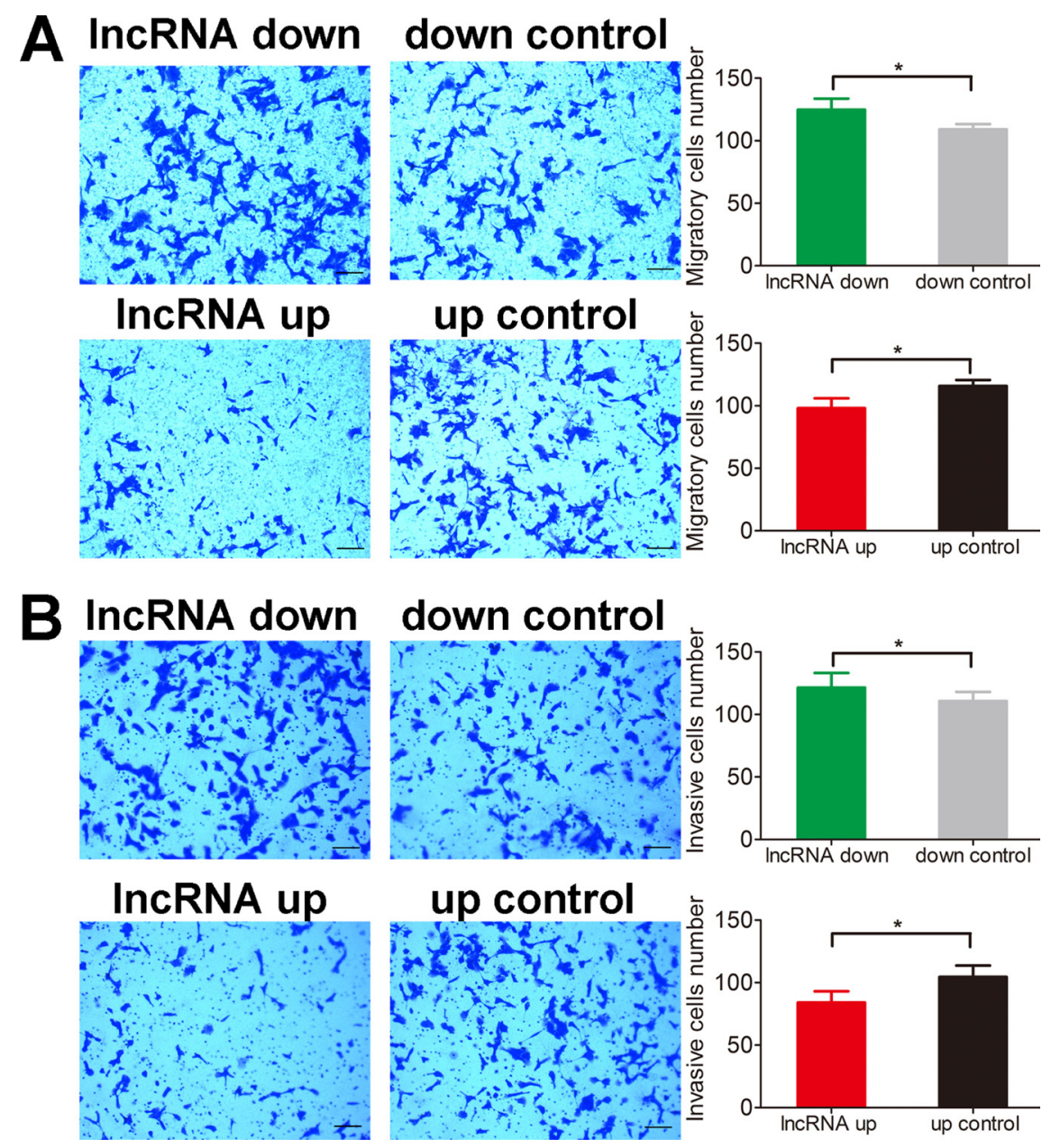

Figure 3: Inc-RAB11B-AS1 impairs migration and invasion of HOS cells. (A) Migration assay of HOS cells with up-regulated or down-regulated lnc-RAB11B-AS1. (B) Transwell invasion assay of HOS cells with up-regulated or down-regulated lnc-RAB11B-AS1. Migration and invasion capacities of osteosarcoma cells were measured by transwell chamber assay, and the photographs were randomly selected and taken at $\times 100$ field. Scale bar, $200 \mu \mathrm{m}$. Data was presented as mean $\pm \mathrm{SD}$. The results were reproducible in three independent experiments. ${ }^{*} P<0.05$. 
is one of the most important chemotherapeutic drugs in conventional chemotherapy for osteosarcoma. However, multiple and complex genetic and epigenetic factors affect the sensitivity of osteosarcoma to cisplatin [30]. In present study, we detected the effect of lnc-RAB $11 B-A S 1$ on cisplatin treatment in osteosarcoma. We found that lnc$R A B 11 B-A S 1$ increased the sensitivity of osteosarcoma cells to cisplatin obviously. Since lnc-RAB11B-AS1 was revealed to inhibit proliferation, migration and invasion and promote the apoptosis of osteosarcoma cells, lnc- $R A B 11 B-A S 1$ is a potential therapeutic target for osteosarcoma.

In conclusion, the present study revealed lnc$R A B 11 B-A S 1$ as an essential molecular marker for osteosarcoma development and progression and a potential therapeutic target for osteosarcoma.

\section{MATERIALS AND METHODS}

\section{Ethics statement}

Each participant was scheduled for an interview to collect individual information and to obtain one pair of osteosarcoma samples and adjacent tissues under his or her informed consent. The study was approved by the institutional review boards of the Third Affiliated Hospital of Southern Medical University.

\section{Sample collection}

Patients with osteosarcoma, who underwent surgery at the Third Affiliated Hospital of Southern Medical University between 2015 and 2016, were retrospectively
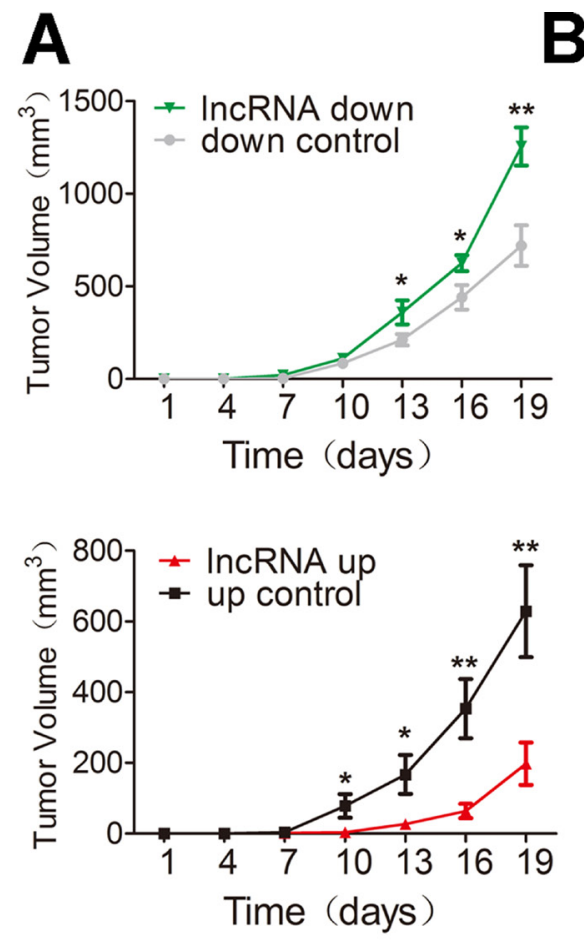

C

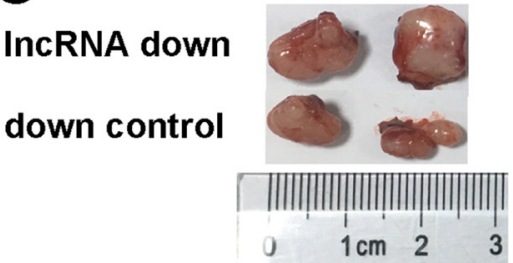

IncRNA up

up control

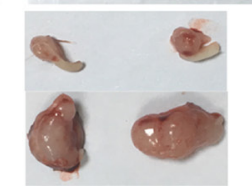

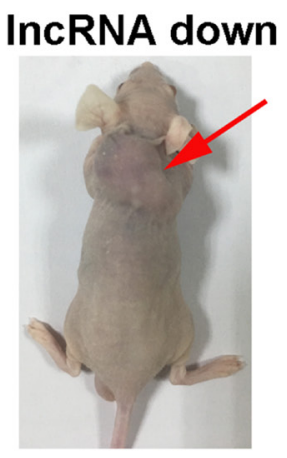
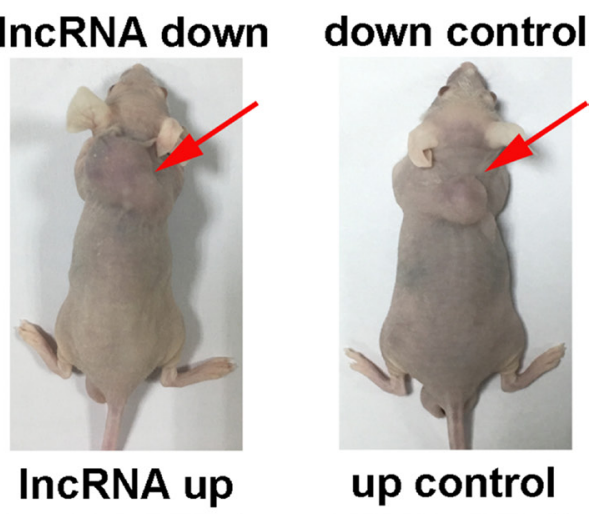

up control

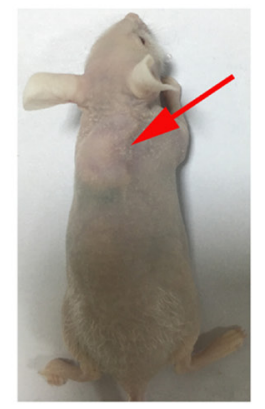

D

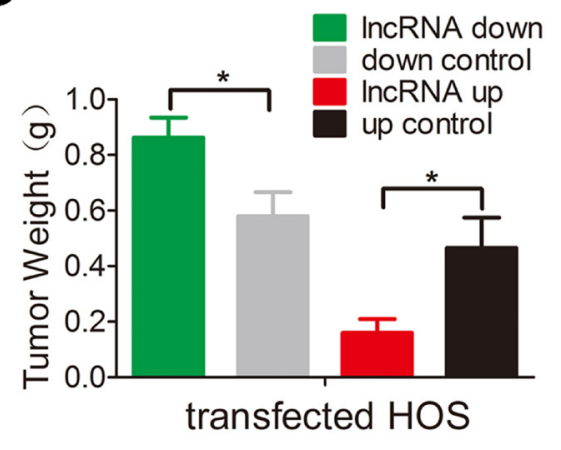

Figure 4: Inc-RAB11B-AS1 inhibits tumor growth in vivo. (A) Mean volumes of 6 nude mice of each group were calculated every three days after injection of transfected HOS cells. (B) Representative photos of mice at 19th day after injection of transfected HOS cells. (C) Representative images of xenografted tumors removed from the mice at 19th day after injection. (D) Average tumor weights of the mice. Data was presented as mean $\pm \mathrm{SD}$. The results were reproducible in three independent experiments. ${ }^{*} P<0.05,{ }^{* *} P<0.01$. 
selected for the present study. A total of 24 pairs of osteosarcoma samples and corresponding non-neoplastic tissues were used. In addition, clinical information and characteristics of patients were also collected.

\section{Cell lines and tissue chip}

The U2OS, Sao-2, MG-63 and MNNG/HOS Cl\#5[R-1059-D] human osteosarcoma cell lines were purchased from the Cellcook Biotech Company (Guangzhou, China). The OS cell lines were cultured at $37^{\circ} \mathrm{C}$ in $90 \%$ humidity and $5 \%$ carbon dioxide $(\mathrm{CO} 2)$ in MEM medium (Gibco, life technologies, California, USA) with $10 \%$ fetal bovine serum (FBS) and penicillin $(100 \mathrm{UI} / \mathrm{mL}) /$ streptomycin $(100 \mathrm{mg} / \mathrm{mL})$ in SANYO AUTOMATIC $\mathrm{CO}_{2}$ INCUBATOR (SANYO Electric Co., Ltd., Japan). The hFOB1.19, human osteoblast transfected by SV40, was purchased from the Yuesui Biotech Company (Guangzhou, China) and it was cultured at $34^{\circ} \mathrm{C}$ in DMEM medium (Gibco, life technologies,
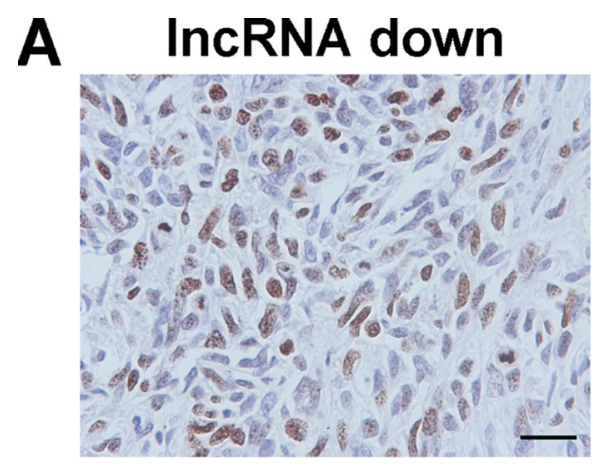

IncRNA up

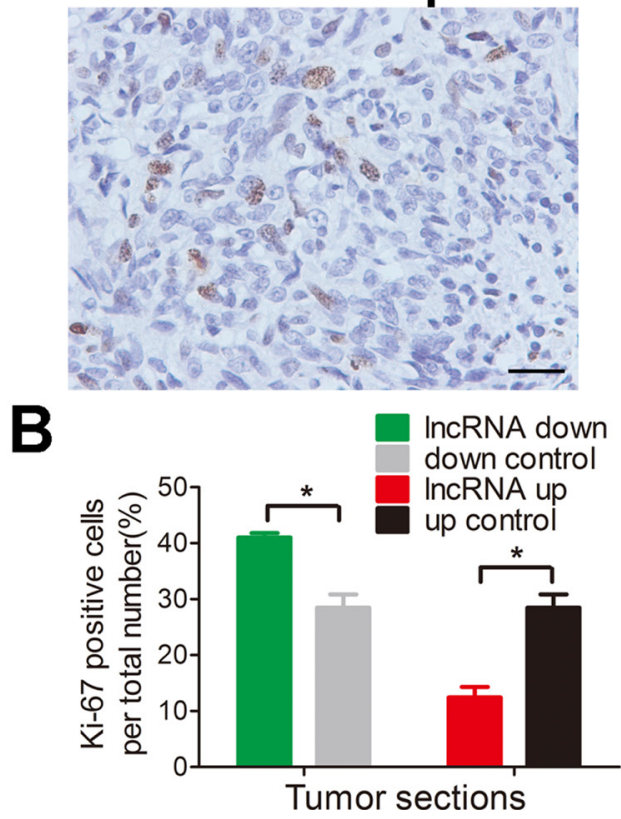

California, USA). The osteosarcoma tissue chips which include 145 cases of osteosarcoma tissue were purchased from Alenabio Company (Xi'an, China).

\section{Quantitative real-time polymerase chain reaction}

All the osteosarcoma tumor tissues and matched adjacent normal tissues were identified using quantitative real-time polymerase chain reaction (qRT-PCR). We also identified the expression level of the related lnc- $R A B 11 B$ $A S 1$ and the target mRNA RAB11B. All primers are listed in the Supplementary Table 1.

\section{Subcellular fractionation}

In order to determine the cellular localization of lnc-RAB11B-AS1, cytosolic and nuclear fractions were collected according to the manufacturer's instructions for nuclear/cytoplasmic isolation kit (Biovision, San Francisco, CA).

\section{down control}
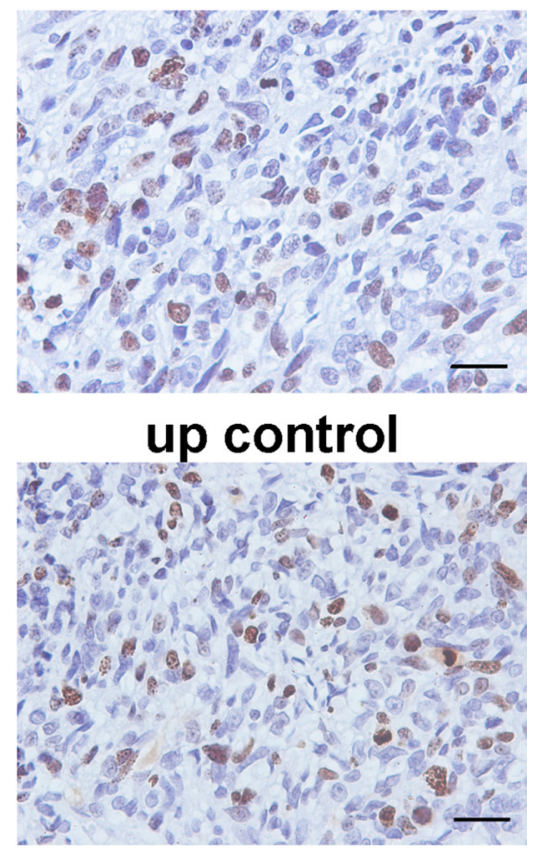

Figure 5: Inc-RAB11B-AS1 inhibits osteosarcoma cells proliferation in vivo. (A) Immunostaining of Ki-67 in osteosarcoma slices (magnification, $\times 400$; scale bar, $100 \mu \mathrm{m}$ ). (B) Quantitative analysis of Ki-67 positive cells over total cells. Data was presented as mean $\pm \mathrm{SD}$. The results were reproducible in three independent experiments. ${ }^{*} P<0.05$. 


\section{Plasmids construction, lentivirus package and transduction}

The full-length complementary DNA of human lnc$R A B 11 B-A S 1$ and small hairpin RNA (shRNA) are both synthesized by iGeneBio (Guangzhou, China). The fulllength complementary DNA of human lnc-RAB11B-AS1 was cloned into the lentiviral expression vector pEZ-Lv206 for over-expression and small hairpin RNA (shRNA) of this human lnc-RAB11B-AS1 was cloned into vector psiLVRH1MP for gene silencing. The resulting construct
(pEZ-Lv206-lnc-RAB11B-AS1 and psi-LVRH1MP- lnc$R A B 11 B-A S 1)$ was verified by sequencing. And the control groups are their respective empty vector. All sequences are listed in the Supplementary Material.

\section{Cell viability and proliferation assay}

Cell viability of cells was measured by using Cell Counting Kit-8 system (CCK-8, Engreen Biosystem Co. Ltd., China) according to the manufacturer's instructions. Proliferation rates were determined at 12,24, 36, 48 and

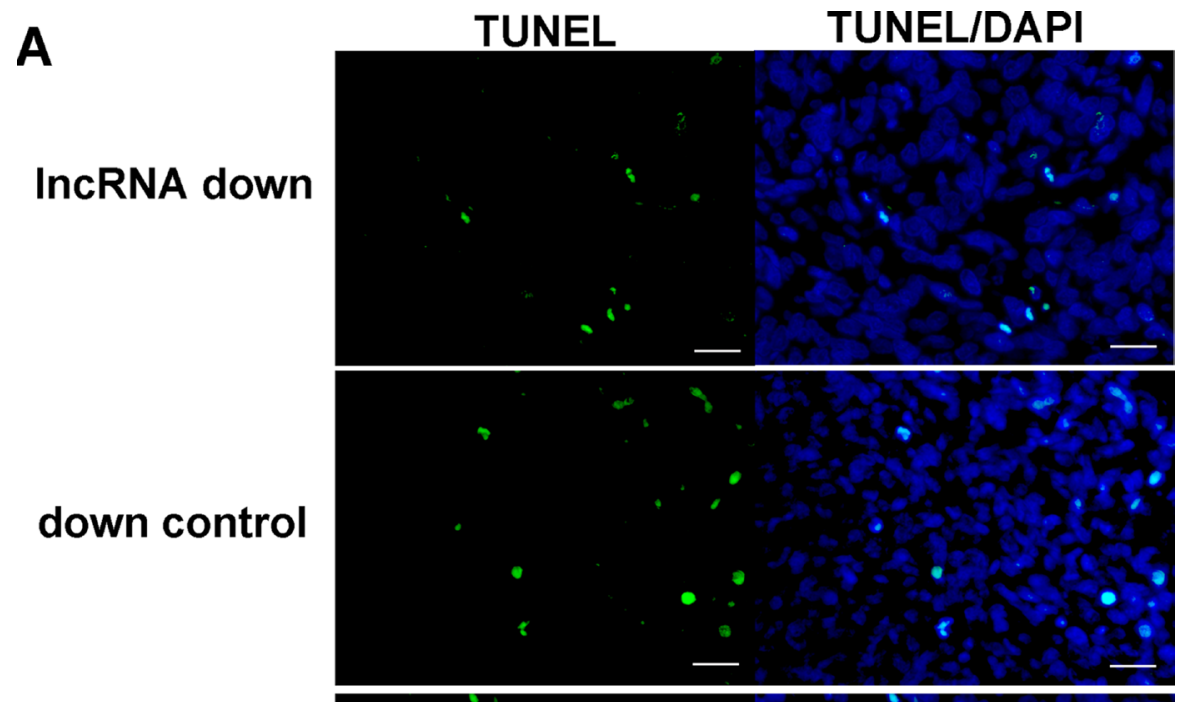

IncRNA up

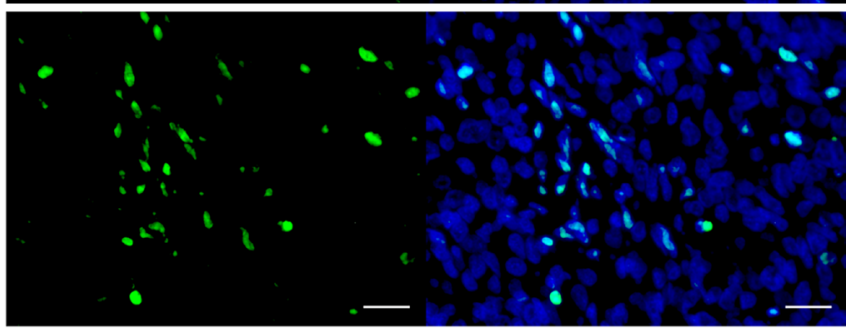

up control
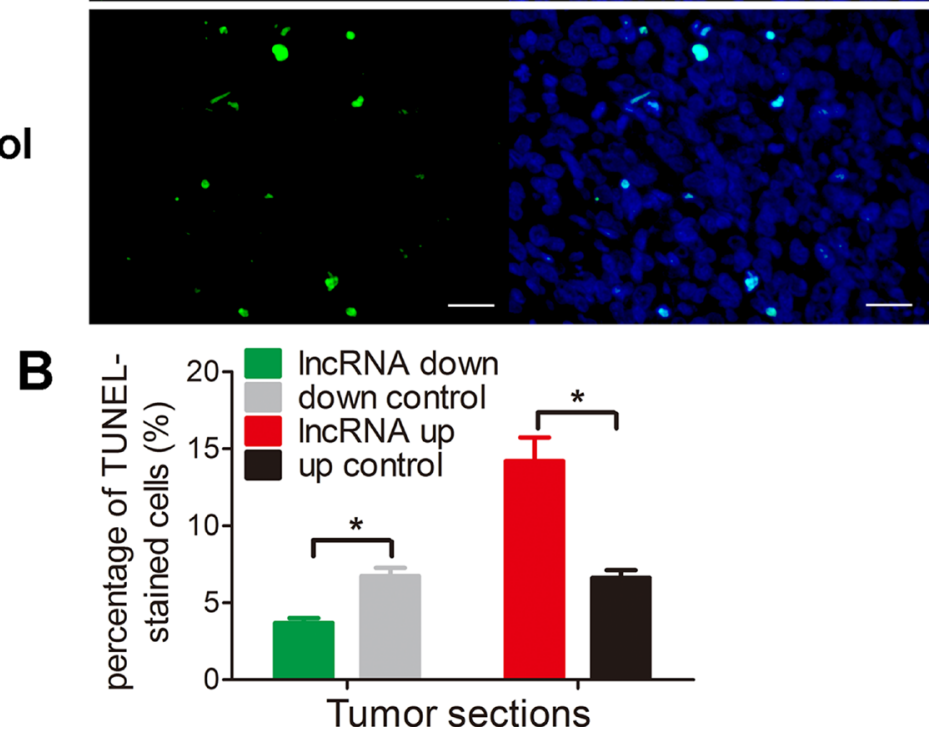

Figure 6: Inc-RAB11B-AS1 promotes cells apoptosis in vivo. (A) Representative images of TUNEL-stained tumor sections. All the images are $400 \times$, scale bar, $100 \mu \mathrm{m}$. (B) Quantitative analysis of TUNEL-positive cells over total cells. Data was presented as mean \pm SD. The results were reproducible in three independent experiments. ${ }^{~} P<0.05$. 

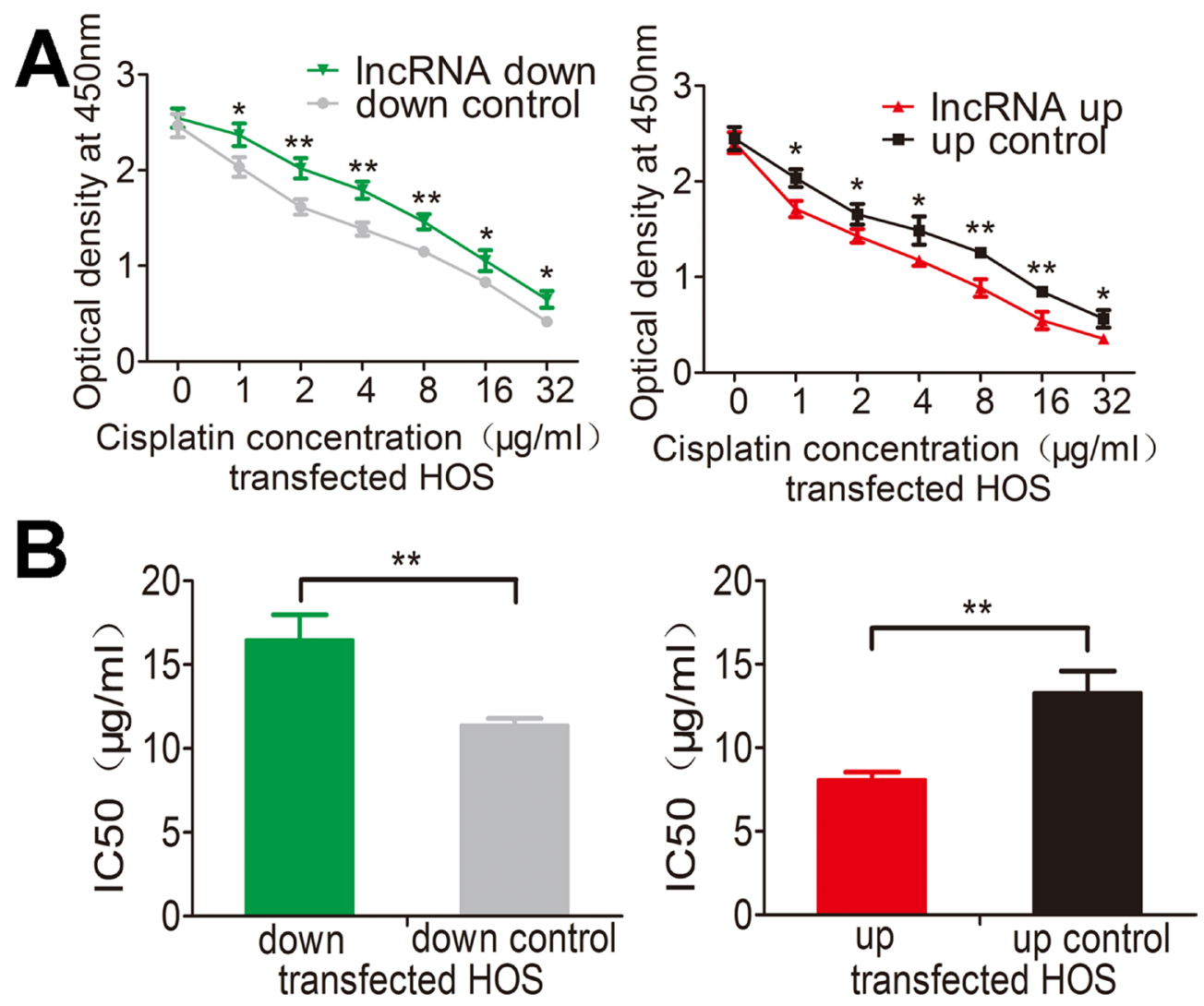

Figure 7: Inc-RAB11B-AS1 elevates sensitivity of HOS cells to cisplatin. (A) HOS cell with down-regulated (down) or upregulated (up) $R A B 11 B-A S 1$ were added with increasing concentration of cisplatin and subjected to CCK-8 assay. (B) HOS cells with lnc-RAB11B-AS1 up-regulation were more sensitive to cisplatin (IC50 $=21.18 \mu \mathrm{g} / \mathrm{ml}$ for lnc-RAB11B-AS1 down-regulation group and $\mathrm{IC} 50=10.57 \mu \mathrm{g} / \mathrm{ml}$ for lnc- $R A B 11 B-A S 1$ up-regulation group). Data was presented as mean $\pm \mathrm{SD}$. The results were reproducible in three independent experiments. ${ }^{*} P<0.05,{ }^{* *} P<0.01$.

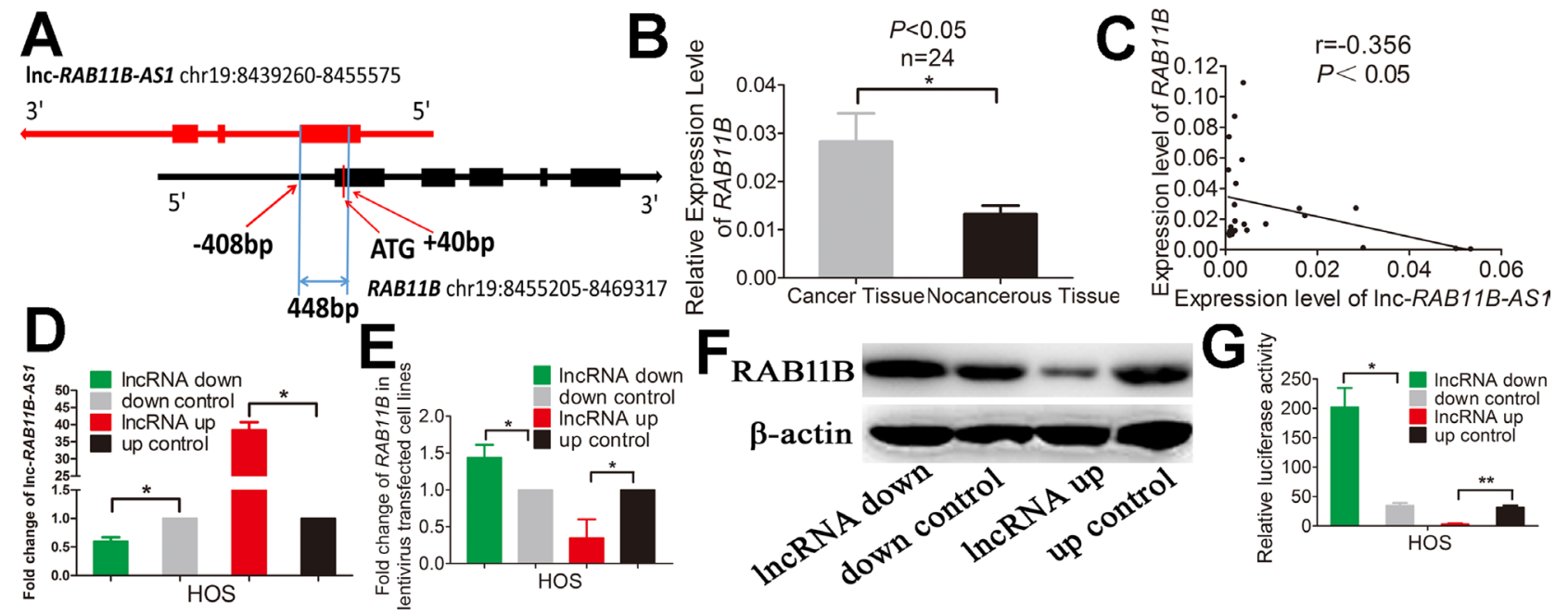

Figure 8: Inc- $R A B 11 B-A S 1$ correlates negatively with its sense-cognate gene RAB11B in HOS cells. (A) Schematic outlining the genomic organization of $\operatorname{lnc}-R A B 11 B-A S 1$ and $R A B 11 B$. Arrows show transcription direction and blocks indicate exons. (B) qRT-PCR analysis of $R A B 11 B$ in the collected osteosarcoma tissues $(n=24)$ and corresponding non-cancerous tissues $(n=24)$. (C) Spearman's correlation analysis showed significant negative correlation between lnc-RAB11B-AS1 and RAB11B expression in osteosarcoma tissues $(\mathrm{r}=-0.356, P<0.05)$. (D) qRT-PCR analysis of RAB11B-AS1 in lentivirus transfected HOS cells. (E) qRT-PCR analysis of RAB11B in HOS cells with down-regulated or up-regulated RAB11B-AS1. (F) Western blot analysis of RAB11B in HOS cells with down-regulated or upregulated RAB11B-AS1. (G)The relative luciferase activity of pGL3-Promoter-RAB11B was markedly increased in the HOS cells with down-regulated lnc-RAB11B-AS1 and was reduced in cells with up-regulated lnc-RAB11B-AS1. Data was presented as mean \pm SD. The results were reproducible in three independent experiments. ${ }^{*} P<0.05,{ }^{* *} P<0.01$. 
60 hours. Cells were incubated in 10\% CCK-8 diluted in normal culture media at $37^{\circ} \mathrm{C}$ until the visual color conversion occurred. The absorbance of each well was measured with a microplate reader set at $450 \mathrm{nM}$.

\section{Cell migration assay and invasive assay}

Cell migration assay was appraised by Corning transwell insert chambers (Costar, Corning Incorporated,
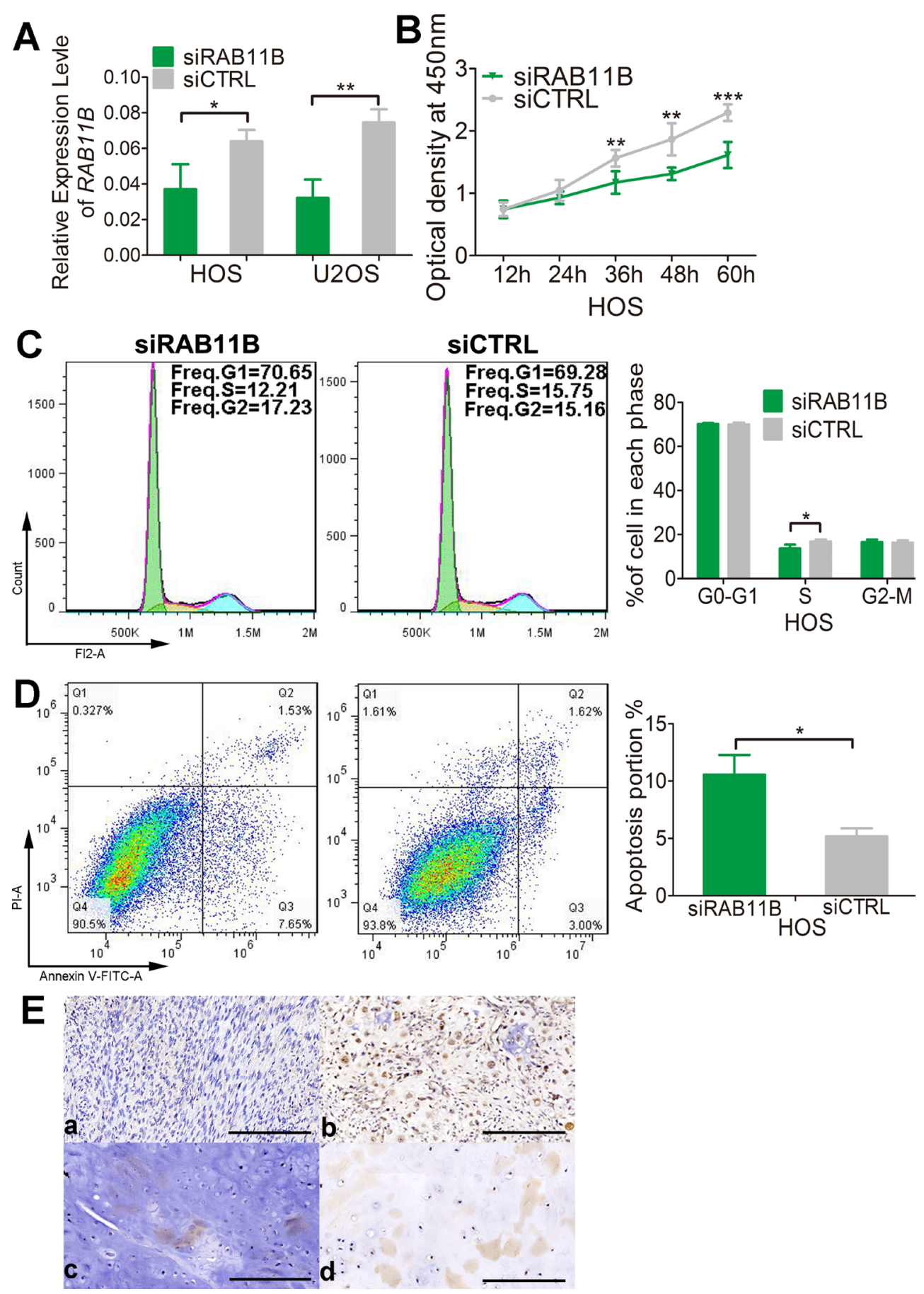

Figure 9: $\boldsymbol{R} \boldsymbol{A B 1 1 B}$ promotes osteosarcoma progression. (A) qRT-PCR analysis of RAB11B in HOS cells and U2OS cells with disrupted RAB11B or not. (B) Proliferation of HOS cells with disrupted RAB11B or not was determined by CCK-8 assay. (C) Flow cytometer analysis of cell cycle distribution in HOS cells with disrupted RAB11B or not. (D) HOS cells with disrupted RAB11B or not were subjected to apoptosis analysis. (E) Analysis of $R A B 11 B$ expression in osteosarcoma tissues $(n=145)$ by immunochemistry. Scale bar, $100 \mu \mathrm{m}$. RAB11B positive cells were stained brown. (a, b) showed RAB11B expression in bone tissue and (c, d) presented $R A B 11 B$ expression in cartilage tissue. Data was presented as mean $\pm \mathrm{SD}$. The results were reproducible in three independent experiments. ${ }^{*} P<$ $0.05,{ }^{* *} P<0.01,{ }^{* * *} P<0.001$. 


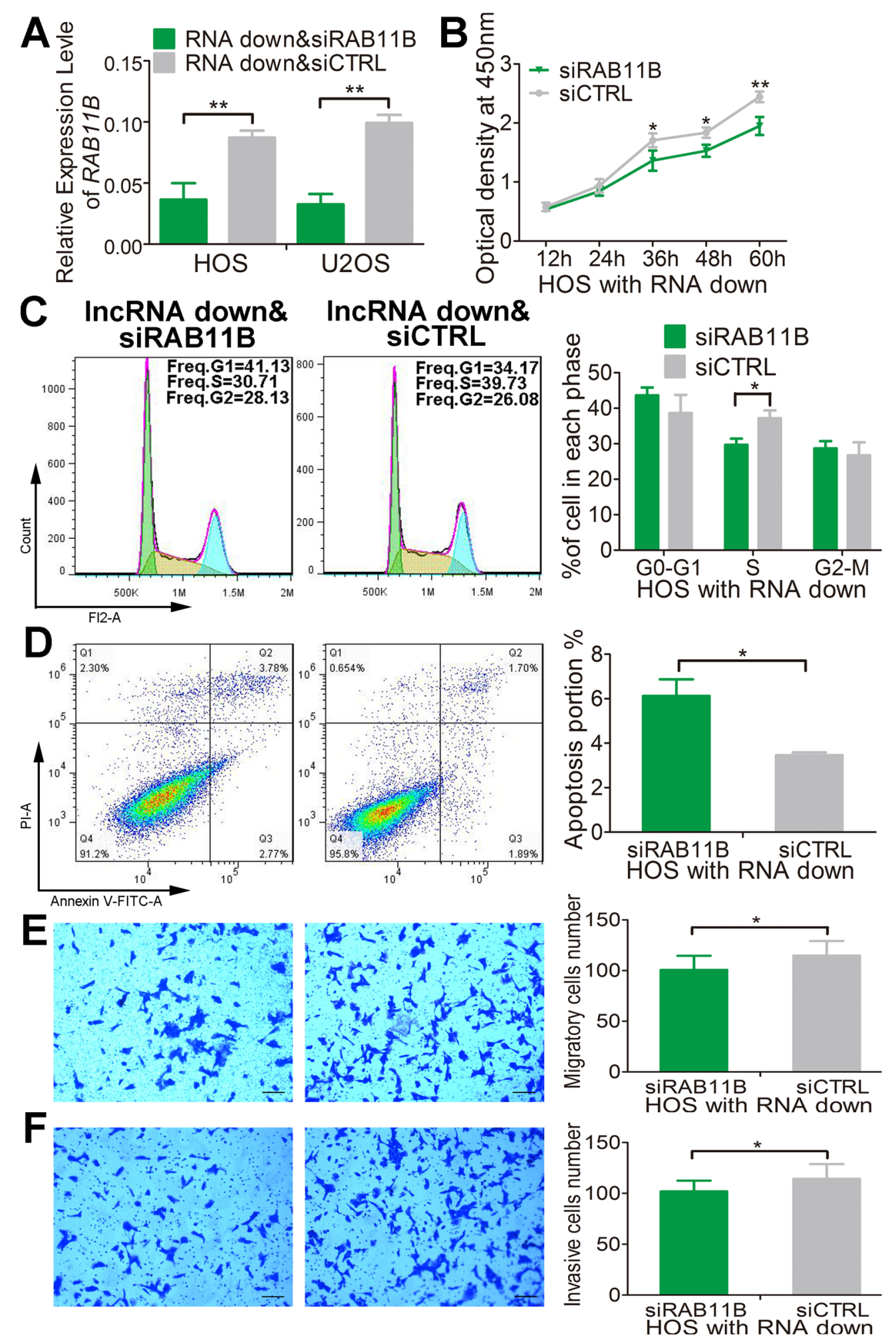

Figure 10: Inc-RAB11B-AS1 prevents HOS cells proliferation via down-regulating $R A B 11 B$. (A) Relative expressions of $R A B 11 B$ were measured by qRT-PCR in HOS and U2OS cells stably down-expressing lnc- $R A B 11 B-A S 1$ and transfected with siRAB11B or siCTRL. (B) HOS cells stably down-expressing lnc-RAB11B- $A S 1$ was interfered with $R A B 11 B$ expression and subjected to proliferation analysis by CCK-8 assay. (C) HOS cells stably down-expressing lnc-RAB11B-AS1 was interfered with si-RAB11B and underwent flow cytometer analysis of cell cycle distribution. (D) HOS cells with stable down-regulated lnc-RAB11B-AS1 was interfered with $R A B 11 B$ expression and subjected to flow cytometer analysis of cell apoptosis. (E) HOS cells stably down-expressing lnc-RAB11B- $A S 1$ was interfered with si-RAB11B and underwent migration assay. (F) HOS cells with stable down-regulated lnc-RAB11B-AS1 was interfered with $R A B 11 B$ expression and subjected to transwell invasion assay. Scale bar, $200 \mu \mathrm{m}$. Data was presented as mean $\pm \mathrm{SD}$. The results were reproducible in three independent experiments. ${ }^{*} P<0.05,{ }^{* *} P<0.01$. 
NY). Cells were grown to near confluence in a $5 \times 5$ culture vessel and then placed in serum-free MEM (Gibco, life technologies, California, USA) for 24 hours. Cells were trypsinized and re-suspended in serum-free MEM with $0.1 \%$ BSA. We planted $2 \times 10^{4}$ cells in the chamber, which was put in a 24-well plate contain MEM with $20 \%$ fetal bovine serum (FBS, Gibco, life technologies, California, USA). After 12 hours culture, non-migrating cell in the top of the chambers were removers by swabbing. Migrated cells were counted manually in 10 random fields and their numbers were averaged. Cells invasive assay was conducted exactly the same, but with an $8-\mu \mathrm{m}$ Corning Matrigel invasive chamber (Corning Incorporated, NY., USA).

\section{Flow cytometry analysis of cell cycle and apoptosis}

In the cell-cycle analysis, cells were labeled with propidium iodide (PI) (sigma, St. Louis, MO) and analyzed by flow cytometry. For apoptosis analysis, Annexin V-fluorescein isothiocyanate (FITC)/PI straining also was performed by using flow cytometry according to the manufacturer's guidelines (MULTISCIENCES, Hangzhou, China).

\section{Luciferase reporter assay}

pGL3-Promoter-RAB11B vector and pGL3Promoter-control vector was co-transfected with lnc$R A B 11 B-A S 1$ up-regulation or down-regulation using Lipofectamine 3000 (Invitrogen) into osteosarcoma cells. The relative luciferase activity was normalized to Renilla luciferase activity $48 \mathrm{~h}$ after transfection. All sequences are listed in the Supplementary Table 2.

\section{Western blot}

Identical quantities of proteins were separated by sodium dodecyl sulfate-polyacrylamide gel electrophoresis (SDS-PAGE), transferred onto PVDF membranes, and subjected to western blot analysis by using anti-RAB $11 B$ (Abcam, USA), following the manufacturer's instructions.

\section{Transient transfection}

The siRNA sequence of $R A B 11 B$ was synthesized by the RIBOBIO CO., LTD (Guangzhou, China). All sequences are listed in the Supplementary Material. The osteosarcoma cells were transfected with si-RAB11B or si-CTRL using Lipofectamine 3000 reagent and Opti-MEM I Reduced

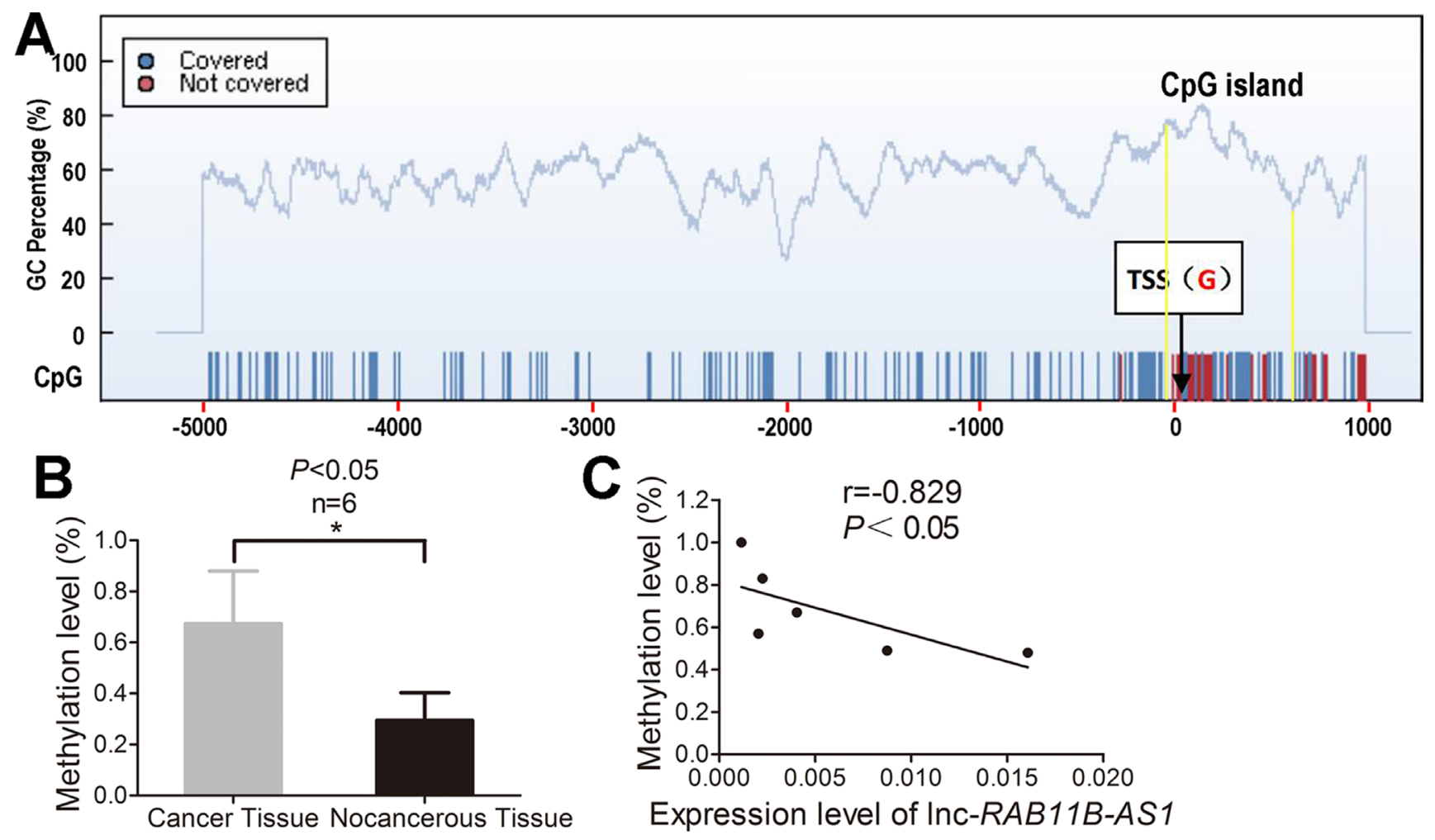

Figure 11: Aberrant hyper-methylation of the promoter region contributes to decresed Inc-RAB11B-AS1 in osteosarcoma. (A) One CpG island from $56 \mathrm{bp}$ upstream to $609 \mathrm{bp}$ downsteam of the transcription start site (TSS) in the promoter region of lnc-RAB11B-ASI was predicted by the $\mathrm{CpG}$ island searcher online software. (B) Mean methylation levels of lnc-RAB11B-ASI in osteosarcoma and paired non-neoplastic tissues. (C) Correlation analysis between mean methylation levels of the promoter region and corresponding $\operatorname{lnc}-R A B 11 B-A S 1$ expressions. Data was presented as mean $\pm \mathrm{SD}$. The results were reproducible in three independent experiments. ${ }^{*} P<0.05$. 
Serum Medium (Gibco, life technologies, California, USA) in accordance with the manufacturer's instructions, respectively.

\section{Susceptibility testing}

We adjusted inoculation quantity to $90 \%$ of each well base area in 96-well plates and then added a concentration gradient of cisplatin $(0 \mu \mathrm{g} / \mathrm{ml}, 1 \mu \mathrm{g} / \mathrm{ml}, 2 \mu \mathrm{g} /$ $\mathrm{ml}, 4 \mu \mathrm{g} / \mathrm{ml}, 8 \mu \mathrm{g} / \mathrm{ml}, 16 \mu \mathrm{g} / \mathrm{ml}, 32 \mu \mathrm{g} / \mathrm{ml})$. After 24 hours, cells were incubated in $10 \%$ CCK- 8 diluted in normal culture media at $37^{\circ} \mathrm{C}$ until the visual color conversion occurred. The absorbance of each well was measured with a microplate reader set at $450 \mathrm{nM}$.

\section{Orthotopic xenotransplantation}

Male BALB/c nude mice aged 5 weeks were purchased from Southern Medical University Animal Center (Guangzhou, China) and maintained under specific pathogen free (SPF) condition in the animal care facility at Southern Medical University. A total of $2 \times 10^{6}$ HOS cells with knockdown, overexpression or controls of lnc-RAB11B-AS1 were suspended in $0.2 \mathrm{ml}$ normal saline and then subcutaneously injected into the back of each mouse. The length $(\mathrm{L}, \mathrm{mm})$ and width $(\mathrm{W}, \mathrm{mm})$ of tumors were measured every 3 days starting the $7^{\text {th }}$ day after inoculation. Tumor volume was calculated using the formula $\mathrm{V}=\mathrm{W}^{2} \mathrm{x} \mathrm{L} \times 0.5$. 19 days later, the mice were euthanized, necropsies were performed, and tumors were weighed. All procedures were monitored in accordance with the ethical standards and the care of animal and licensing guidelines, under the protocol approved by the Committee on Animal Welfare of Southern Medical University.

\section{Immunohistochemistry}

Tissues were blocked by $10 \%$ formalin and embedded in paraffin. The paraffin-embedded tissues were cut into $4 \mu \mathrm{m}$-thick section and then the sections were dewaxed in xylene and rehydrated in a graded alcohol series. Antigen retrieval was conducted. $\mathrm{H}_{2} \mathrm{O}_{2}(3 \%)$ was used to suppress endogenous peroxidase activity. Polyclonal rabbit antibody at 1:100 dilution against Ki-67 (Abcam, USA) was added and incubated at $4^{\circ} \mathrm{C}$ overnight. After washing, sections were incubated with anti-rabbit secondary antibody at $1: 100$ dilution for $1 \mathrm{~h}$ at $37^{\circ} \mathrm{C}$. Staining was detected by diaminobenzidine (DAB). Sections were counterstained with hematoxylin.

\section{TUNEL staining}

To detect apoptotic cells on the same sections, TUNEL staining was performed using DeadEnd ${ }^{\mathrm{TM}}$ Fluorometric TUNEL System (G3250, Promega, America) following the manufacturer's protocol. The samples were mounted in ProLong Gold antifade mountant with DAPI (Invitrogen, America). Images were obtained using an AXIO-Scope.A1 (ZEISS, Germany). These counts were averaged to obtain the number of apoptotic cells per specimen.

\section{CpG island prediction}

The lnc-RAB11B-AS1 sequence (5000 bp upstream of the TSS to $1000 \mathrm{bp}$ downsteam of the TSS) was download from NCBI (https://www.ncbi.nlm.nih.gov/) and predicted the distribution of $\mathrm{CpG}$ islands using the $\mathrm{CpG}$ island searcher online software (http:/www.ebi. ac.uk/Tools/seqstats/emboss_cpgplot/) with the parameters set as lower limits: (\%GC $>50$, ObsCpG/ExpCpG>0.6, length $>200$ ).

\section{DNA methylation sequencing by MassArray}

The pair of primers spanning predicted
$\begin{aligned} & \mathrm{CpG} \text { islands of } \\ & \text { designed using the } \text { EpiDesigner software }\end{aligned}$
(http://www.epidesigner.com). Primer sequences were: forward primer: $5^{\prime}$-aggaagagagAATTTTGGGA AAGTTTTATTTTTTG-3'; reverse primer: 5'- cagtaatacgactcactatagggagaaggct CCTCAAAACACTACTTCCATCTCTA-3'. Genomic DNA was extracted from 6 osteosarcoma specimens and their adjacent normal tissues using the genomic DNA extraction kit (BioTeKe Corpration, Beijing, China). The genomic DNA from each sample was treated with sodium bisulfite using an EZ DNA methylation kit (Zymo Research, Orange, CA). Quantitative methylation analyses of the CpG sites were performed using the Sequenom MassARRAY platform (CapitalBio, Beijing, China). The spectral methylation ratios were analyzed with EpiTyper software version 1.0 (Sequenom, San Diego, CA, USA).

\section{Statistics}

All results are presented as the mean \pm S.D. Difference between groups were assessed by student's $t$-test (two tailed). The relationship between lnc-RAB11B- $A S 1$ and $R A B 11 B$ expression was analyzed by Pearson's correlation. Others comparisons were determined by $\chi^{2}$ test or Analysis of Variance (ANOVA). The SPSS 18.0 software package (SPSS, Chicago, IL, USA) was used for statistical analysis. The $P$ value less than 0.05 was considered to be significant.

\section{Author contributions}

Z.C., Z.L. conceived the ideas for experimental designs, analyzed data and wrote the manuscript. Z.C. conducted the majority of the experiments. B.H. collected tissue samples and the clinical information. Y.Y., Z.Z., D.W. conducted cell cultures and western blot experiments. 
R.L. conducted qRT-PCR. Q.L., D.J., H.L., L.Y developed the concept, supervised the project, conceived the experiments and critically reviewed the manuscript.

\section{CONFLICTS OF INTEREST}

The authors declare no conflicts of interest.

\section{FUNDING}

This research was supported by grants 81672120 (D.J.) and 81700783(B.H.) from National Natural Sciences Foundation of China.

\section{REFERENCES}

1. Duchman KR, Gao Y, Miller BJ. Prognostic factors for survival in patients with high-grade osteosarcoma using the Surveillance, Epidemiology, and End Results (SEER) Program database. Cancer Epidemiol. 2015; 39:593-9.

2. Picci P. Osteosarcoma (osteogenic sarcoma). Orphanet J Rare Dis. 2007; $2: 6$.

3. Bacci G, Longhi A, Versari M, Mercuri M, Briccoli A, Picci P. Prognostic factors for osteosarcoma of the extremity treated with neoadjuvant chemotherapy: 15-year experience in 789 patients treated at a single institution. Cancer. 2006; 106:1154-61.

4. Jawad MU, Cheung MC, Clarke J, Koniaris LG, Scully SP. Osteosarcoma: improvement in survival limited to high-grade patients only. J Cancer Res Clin Oncol. 2011; 137:597-607.

5. Mirabello L, Troisi RJ, Savage SA. Osteosarcoma incidence and survival rates from 1973 to 2004: data from the Surveillance, Epidemiology, and End Results Program. Cancer. 2009; 115:1531-43.

6. Rao-Bindal K, Kleinerman ES. Epigenetic regulation of apoptosis and cell cycle in osteosarcoma. Sarcoma. 2011; 2011:679457.

7. Caley DP, Pink RC, Trujillano D, Carter DR. Long noncoding RNAs, chromatin, and development. Sci World J. 2010; 10:90-102.

8. Johnsson P, Lipovich L, Grander D, Morris KV. Evolutionary conservation of long non-coding RNAs; sequence, structure, function. Biochim Biophys Acta. 2014; 1840:1063-71.

9. Khachane AN, Harrison PM. Mining mammalian transcript data for functional long non-coding RNAs. PLoS One. 2010; 5:e10316.

10. Yang X, Xie X, Xiao YF, Xie R, Hu CJ, Tang B, Li BS, Yang SM. The emergence of long non-coding RNAs in the tumorigenesis of hepatocellular carcinoma. Cancer Lett. 2015; 360:119-24.
11. Liu Y, Zhang R, Ying K. Long noncoding RNAs: novel links in respiratory diseases (review). Mol Med Rep. 2015; 11:4025-31.

12. Ye LC, Zhu X, Qiu JJ, Xu J, Wei Y. Involvement of long non-coding RNA in colorectal cancer: From benchtop to bedside (Review). Oncol Lett. 2015; 9:1039-45.

13. Li Z, Zhao L, Wang Q. Overexpression of long non-coding RNA HOTTIP increases chemoresistance of osteosarcoma cell by activating the Wnt/beta-catenin pathway. Am J Transl Res. 2016; 8:2385-93.

14. Sun J, Wang X, Fu C, Wang X, Zou J, Hua H, Bi Z. Long noncoding RNA FGFR3-AS1 promotes osteosarcoma growth through regulating its natural antisense transcript FGFR3. Mol Biol Rep. 2016; 43:427-36.

15. Ruan W, Wang P, Feng S, Xue Y, Li Y. Long non-coding RNA small nucleolar RNA host gene 12 (SNHG12) promotes cell proliferation and migration by upregulating angiomotin gene expression in human osteosarcoma cells. Tumour Biol. 2016; 37:4065-73.

16. Kelly EE, Horgan CP, McCaffrey MW. Rab11 proteins in health and disease. Biochem Soc Trans. 2012; 40:1360-7.

17. Gebhardt C, Breitenbach U, Richter KH, Fürstenberger G, Mauch C, Angel P, Hess J. c-Fos-dependent induction of the small ras-related GTPase Rab11a in skin carcinogenesis. Am J Pathol. 2005; 167:243-53.

18. Chung YC, Wei WC, Huang SH, Shih CM, Hsu CP, Chang KJ, Chao WT. Rab11 regulates E-cadherin expression and induces cell transformation in colorectal carcinoma. BMC Cancer. 2014; 14:587.

19. Jing J, Tarbutton E, Wilson G, Prekeris R. Rab11-FIP3 is a Rab11-binding protein that regulates breast cancer cell motility by modulating the actin cytoskeleton. Eur J Cell Biol. 2009; 88:325-41.

20. Katayama S, Tomaru Y, Kasukawa T, Waki K, Nakanishi M, Nakamura M, Nishida H, Yap CC, Suzuki M, Kawai J, Suzuki H, Carninci P, Hayashizaki Y, et al. and FANTOM Consortium. Antisense transcription in the mammalian transcriptome. Science. 2005; 309:1564-6.

21. Faghihi MA, Modarresi F, Khalil AM, Wood DE, Sahagan BG, Morgan TE, Finch CE, St Laurent G 3rd, Kenny PJ, Wahlestedt C. Expression of a noncoding RNA is elevated in Alzheimer's disease and drives rapid feed-forward regulation of beta-secretase. Nat Med. 2008; 14:723-30.

22. Gupta RA, Shah N, Wang KC, Kim J, Horlings HM, Wong DJ, Tsai MC, Hung T, Argani P, Rinn JL, Wang Y, Brzoska P, Kong B, et al. Long non-coding RNA HOTAIR reprograms chromatin state to promote cancer metastasis. Nature. 2010; 464:1071-6.

23. Carrieri C, Cimatti L, Biagioli M, Beugnet A, Zucchelli S, Fedele S, Pesce E, Ferrer I, Collavin L, Santoro C, Forrest AR, Carninci P, Biffo S, et al. Long non-coding antisense RNA controls Uchl1 translation through an embedded SINEB2 repeat. Nature. 2012; 491:454-7. 
24. Chen N, Guo D, Xu Q, Yang M, Wang D, Peng M, Ding Y, Wang S, Zhou J. Long non-coding RNA FEZF1-AS1 facilitates cell proliferation and migration in colorectal carcinoma. Oncotarget. 2016; 7:11271-83. https://doi. org/10.18632/oncotarget.7168.

25. Chen M, Zhuang C, Liu Y, Li J, Dai F, Xia M, Zhan Y, Lin J, Chen Z, He A, Xu W, Zhao G, Guo Y, et al. Tetracyclineinducible shRNA targeting antisense long non-coding RNA HIF1A-AS2 represses the malignant phenotypes of bladder cancer. Cancer Lett. 2016; 376:155-64.

26. Xu S, Wang P, You Z, Meng H, Mu G, Bai X, Zhang G, Zhang J, Pang D. The long non-coding RNA EPB41L4AAS2 inhibits tumor proliferation and is associated with favorable prognoses in breast cancer and other solid tumors. Oncotarget. 2016; 7:20704-17. https://doi.org/10.18632/ oncotarget. 8007 .
27. Chak WP, Lung RW, Tong JH, Chan SY, Lun SW, Tsao SW, Lo KW, To KF. Downregulation of long non-coding RNA MEG3 in nasopharyngeal carcinoma. Mol Carcinog. 2017; 56:1041-54.

28. Liao M, Li B, Zhang S, Liu Q, Liao W, Xie W, Zhang Y. Relationship between LINC00341 expression and cancer prognosis. Oncotarget. 2017; 8:15283-93. https://doi. org/10.18632/oncotarget.14843.

29. Zhang C, Wang X, Li X, Zhao N, Wang Y, Han X, Ci C, Zhang J, Li M, Zhang Y. The landscape of DNA methylation-mediated regulation of long non-coding RNAs in breast cancer. Oncotarget. 2017; 8:51134-50. https://doi. org/10.18632/oncotarget.17705.

30. Isakoff MS, Bielack SS, Meltzer P, Gorlick R. Osteosarcoma: Current Treatment and a Collaborative Pathway to Success. J Clin Oncol. 2015; 33:3029-35. 